\title{
Longstanding effect of recurrent Otitis Media with effusion on central auditory processing in Children
}

Iman A. Bahader $1^{*}$, Hedayat Elfouly 2, Mona H. Selim 2 \& Maha H. Abou-elew 2

1 Department of child Health, National research center, Cairo, Egypt

2 Audiology unit of ENT department, Cairo University, Egypt.

*Corresponding Author: Iman.bahader@med.uni-goettingen.de

\section{ABSTRACT}

Background: Auditory deprivation due to otitis media with effusion (OME) has been suggested and could be related to auditory processing problem. Aim of the work: To assess central auditory processing functions in children having recurrent OME through behavioral and electrophysiological testing, and to correlate between them. Methodology: Sixty children of both genders were enrolled in this study and divided into 30 children with history of recurrent OME and 30 children of age and gender matched control group. All children were subjected to full history taking, basic audiological evaluation, speech intelligibility in noise test (SPIN), click evoked auditory brainstem response (click ABR) and speech evoked auditory brainstem response testing (speech ABR). Results: Comparing both groups revealed statistically significant depressed SPIN scores at different signal to noise ratios in study group even in absence of conductive hearing loss (CHL). Click ABR absolute latencies of wave I, III and $\mathrm{V}$ and interpeak latencies I-V and III-V were significantly prolonged due to $\mathrm{CHL}$. Speech ABR showed significant wave $V$ latency shift together with wave A delay, reduced amplitude, prolonged $V-A$ duration and shallower slope even in absence of hearing loss. Conclusion: Children having recurrent OME showed brainstem abnormalities as detected by SPIN, click $A B R$ and speech ABR tests even in absence of hearing loss.

Keywords: Otitis media with effusion (OME), conductive hearing loss $(\mathrm{CHL})$, speech auditory brainstem response (speech $\mathrm{ABR}$ ) and speech intelligibility in noise test (SPIN). 


\section{INTRODUCTION}

Otitis media with effusion (OME) is one of the most common childhood diseases, affecting about two third of children in the first 5 years of life (1). The high incidence of OME in children highlights the possible negative impact that OME may have on the developing population. The mild to moderate predominantly low frequency conductive hearing loss associated with the disorder has both short and possibly long-term effects on the auditory and subsequent language development of the population (2).

OME causes accumulation of fluid in middle ear, which interferes the speech perception, causing a distortion in the perception of acoustic signal and reduce the accuracy and the speed of verbal decoding. When hearing fluctuation occurs early in life, that is the critical period for linguistic development, a limited acquisition of speech and language occurs. This can results in language development impairment, central auditory processing deficits and cognitive functions affection (1).

Auditory processing disorder (APD) is diagnosed based on difficulty in identifying or discriminating sounds despite normal peripheral hearing. APD may manifest as a deficit in speech perception in noise, sound localization, discrimination, pattern recognition, temporal processing, following oral instructions and performance deficits when the auditory signal is degraded or embedded in competing acoustic signals. Difficulty in understanding speech in noise is the most common manifestation. Symptoms may become apparent in the early school years or at a later academic stage of the child's life due to changes in the acoustic environment and increase in the acoustic demands (3).

These deficits have electrophysiological as well as behavioral correlates. An example for behavioral central auditory tests is monaural low redundancy: speech stimuli that are either degraded (e.g. in terms of frequency content) or embedded in competing signals (e.g. in noise or multispeaker babble) presented to one ear and the child is requested to identify the speech stimulus. 
Electrophysiological tests used for detection of APD may include auditory brain stem evoked responses (4).

Speech evoked ABR using the synthesized speech stimulus /da/can be a useful, non-invasive and a new objective tool to screen or identify patients with abnormal speech processing or perhaps those with auditory processing disorders. It carries more diagnostic data than click evoked ABR. (5) and the use of naturally uttered speech to evoke ABR allow the design of engaging behavioral tasks, facilitating new investigations of the effects of cognitive processes like language processing and attention on brainstem processing $\{6\}$.

Although OME has very high incident rate childhood, yet few studies have been reported on the effect of conductive hearing loss caused by recurrent otitis media on central auditory processing in those children. Therefore, this study was conducted to address this issue, assessing central auditory function in children with recurrent otitis media through behavioral test (SPIN test) and electrophysiological tests (click and speech ABR).

\section{SUBJECTS AND METHODS}

\section{A- Subjects:}

Participants in this study were selected from the Audiology Outpatient Clinic or referred from ENT clinic (Cairo University Hospitals) having history of recurrent attacks of otitis media. Normal children were included in the study to serve as an age matched control group.

Sixty participants of both genders were included in this study with age ranging from 5 to 14 years. They were divided into 2 groups: 30 normal control subjects and 30 patients with history of recurrent otitis media. Consent was obtained from parents or guardians of all children participating in this study. The ethical committee of National Research center approved the protocol of this study. 
A detailed history was taken from parents about the onset, number and duration of attacks of OME. Any previous audiological evaluations with subsequent treatment and scholastic achievement were assessed. The study group included in this study must have history of recurrent attacks of otitis media with effusion ( 3 episodes within 6 months or $\geq 4$ episodes within 1 year). They have variable middle ear pressure (as detected by tympanometry) whether normal or abnormal tympanogram with subsequent variable hearing threshold level whether normal peripheral hearing or conductive hearing loss on the examination day. Meanwhile patients with perforated TM, sensorineural or mixed hearing loss, congenital craniofacial malformation or subnormal IQ or any neurological, speech and language disorder were excluded from this study.

\section{B-Methods:}

Both groups in this study were subjected to the following:

1. Careful History taking: Including symptoms of balance problems.

\section{Otoscopic examination.}

\section{Tunning fork tests.}

\section{Pure tone audiometry (PTA):}

- $\quad$ Air conduction at octave frequencies from $250-8000 \mathrm{~Hz}$.

- $\quad$ Bone conduction at octave frequen cies from $500-4000 \mathrm{~Hz}$.

5-Speech audiometry: including:

a) Speech reception threshold (SRT) using Arabic spondaic words (7).b) Speech discrimination

- Word discrimination score (WRS) using Arabic phonetically balanced (PB) kindergarten words (8).

- Speech intelligibility in noise (SPIN) test: Speech intelligibility in noise test is a suprathreshold test. It was presented monoaurally via earphones at $40 \mathrm{~dB} S \mathrm{SL}$. The speech and noise were presented to the same ear at $0 \mathrm{~dB},-5 \mathrm{~dB}$ and $10 \mathrm{~dB}$ signal to noise ratio (SNR) respectively. The key factor in speech in 
noise test is SNR. When SNR is $0 \mathrm{~dB}$ this indicates that equal sound pressure of speech to the overall noise. Speech in noise test was administrated using Arabic sentences of variable lengths (9). Narrow band noise (NBN) is the type of noise selected and the subject was instructed to repeat the sentence presented to the designated ear. At each SNR, 10 sentences were presented to each ear. Each sentence constituted $10 \%$ of the total correct score. Scoring of $10 \%$ of each sentence was distributed according to the keywords in that sentence.

6-Tympanometry: Using single frequency tympanometry with a probe tone of $226 \mathrm{~Hz}$. 7-Testing of the acoustic reflex: Testing of the acoustic reflex for the ipsilateral elicited reflexes using pure tones at frequency octaves 500, 1000, 2000 and 4000 Hz.8- Auditory Brainstem Response (ABR): Recording was carried out with the subject lying down after good skin preparation. Silver-chloride disposable electrodes were attached to the scalp. Electrodes were mounted with the recording electrode on the forehead, the reference electrode on the ipsilateral mastoid, and the ground electrode on the contralateral mastoid.

\section{The following parameters were used:Two types of stimuli:}

1. Click : Rarefaction click with a duration of $100 \mu \mathrm{sec}$ and repetition rate of 11 pps.

- Time window: 22ms

- Sweep count: 1024

- Intensity: 80dBnHL

- Gain: 100,000

- Filter settings from 100-1500 Hz.

2. Speech stimulus: alternative speech /da/ stimulus with a repetition rate of $11 / \mathrm{s}$ (both click and speech ABR were recorded with the same repetition rate in the same trace in order to compare between wave $V$ elicited by either stimuli).

- Time window: 22ms

- Sweep count: 1024-2000 
- Intensity: 80dBnHL

- Gain: 100,000

- Filter settings from 300 to $3000 \mathrm{~Hz}$

\section{Equipment:}

1. Audiometer: Two channel audiometry, Grason - Stadlerlnc (GSI)-Eden Prairie, MN, USA, model 61 using headphones TDH 39 and bone vibrator radio $B 71$.

2. Sound treated room: The sound treated room used was Amplisilence Model E.

3. Immitancemeter: Interacoustic AZ 26 with a probe tone $220 \mathrm{~Hz}$, manufactured by Interacoustics, Denmark, calibrated according to the ISO standards.

4. Auditory evoked brainstem response audiometer: Two channels auditory evoked potential system; model Biologic Navigator (EP 317), Natus Medical incorporated, San Carlos, USA.

Statistical analysis: Statistical Package of Social Science Software program, version 17 (SPSS) was used to analyze data.

\section{RESULTS}

The current study was conducted on a total number of 60 participants and they were divided into two groups (control and study group).

The control group: It comprised 30 children with normal peripheral hearing with no previous history of recurrent $\mathrm{OM}$, their age ranged from 5 to 14 years (their mean age was 10.43 \pm 2.07$)$. It included 14 males and 16 females.

The study group: It comprised 30 children with history of recurrent $\mathrm{OM}$, their age ranged from 6 to 12 years (their mean age was $10.21 \pm 2.61$ ). It included 17 males and 13 females. Gender and age distribution were matched between control and study groups ( $\mathrm{p}=0.425$ and 0.310 respectively).

-The clinical characteristics of the study group are summarized in Table (2).

Table (1): Clinical data of patients included in the study ( $n=30$ patients). 


\begin{tabular}{|c|c|c|}
\hline & Number & Percentage \\
\hline $\begin{array}{l}\text { Present history (Mean } \pm S D \text { ) } \\
\text { - } \quad \text { Duration of the disease (years) } \\
\text { - Age of first attack (years) } \\
\text { Past history of: } \\
\text { - } \quad \text { Balance problems } \\
\text { - Scholastic underachievement } \\
\text { - Adenoidectomy } \\
\text { Once } \\
\text { Twice } \\
\text { - GT insertion: } \\
\text { In both ears: }\end{array}$ & $\begin{array}{l}2.76 \pm 1.06 \\
4.54 \pm 2.13 \\
7 \\
9 \\
16 \\
17 \\
2 \\
5 \\
2\end{array}$ & $\begin{array}{l}23.3 \% \\
30 \% \\
53.3 \% \\
56.7 \% \\
6.7 \% \\
16.6 \% \\
6 \%\end{array}$ \\
\hline $\begin{array}{l}\text { Otoscopic exam. } \\
\text { TM (n=60 ears) } \\
\text { Normal } \\
\text { Retracted } \\
\text { Bulging } \\
\text { Grommets in place } \\
\text { Scars } \backslash \text { Opacity } \\
\text { Perforations }\end{array}$ & $\begin{array}{l}16 \\
22 \\
3 \\
4 \\
8 \\
7\end{array}$ & $\begin{array}{l}26.7 \% \\
36.7 \% \\
5 \% \\
6.7 \% \\
18.3 \% \\
23.3 \%\end{array}$ \\
\hline
\end{tabular}

According to the average hearing threshold level from $0.5 \mathrm{KHz}$ to 4 $\mathrm{KHz}$ the patients were sub classified according to Clark (1981)(10) classification into (Figure 1):

Subgroup 1: It included patients with normal peripheral hearing (up to $15 \mathrm{~dB}$ ) and they were 26 ears ( 7 in both ears and 12 in one ear). 
Subgroup 2: It included patients with hearing loss; they were 34 ears and subdivided as the following:

1. Subgroup 2a: patients with slight hearing loss (from 15 to $25 \mathrm{~dB}$ ) and they were 17 ears ( 2 patients affected in both ears and 13 patients affected in one ear).

2. Subgroup $2 \mathrm{~b}$ : patients with mild hearing loss ( $>25$ to $40 \mathrm{~dB}$ ) and they were 10 ears ( 2 patients affected in both ears and 6 patients affected in one ear).

3. Subgroup 2c: patients with moderate hearing loss ( $>40$ to $55 \mathrm{~dB}$ ) they were 4 ears (4 patients affected in one ear).

4. Subgroup $2 \mathrm{~d}$ : patients with moderately severe hearing loss ( $>55$ to 70 $\mathrm{dB}$ ) they were 3ears (1patient affected in both ears and 1 patient affected in one ear).

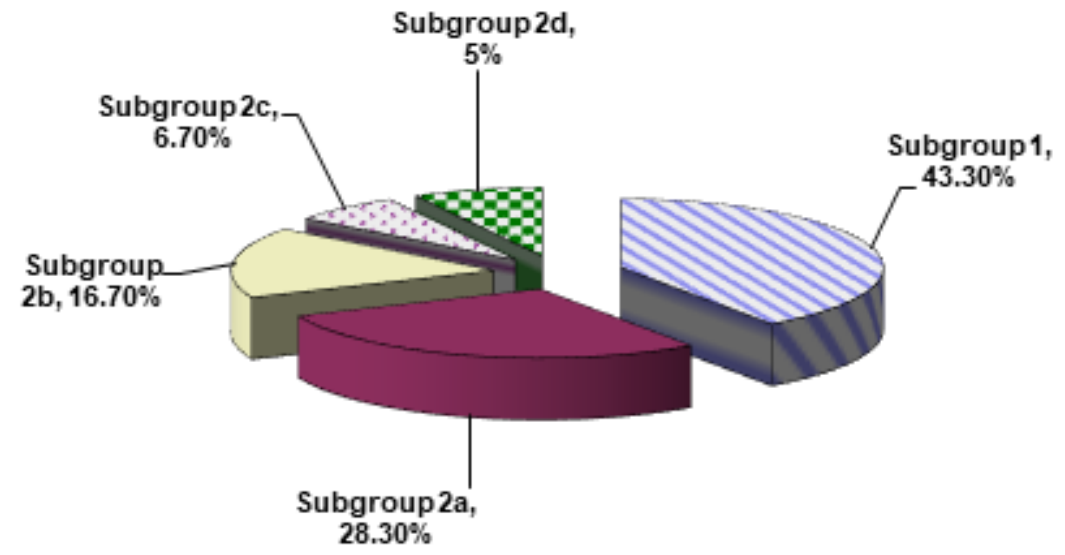

Figure (1): PTA average hearing threshold in patients participated in the study. 
-Speech discrimination test in quiet revealed statistically significant reduced score in the study group compared to control groups on both sides $(p=0.000)$. Speech perception in noise revealed the same statistically significant difference between control and study groups at SNR $0 \mathrm{~dB}(\mathrm{p}=0.001$ and 0.002 on right and left side respectively), $-5 \mathrm{~dB} \quad(p=0.001$ and 0.000 on right and left side respectively) and at $-10 \mathrm{~dB}$ ( $\mathrm{p}=0.000$ on both sides) as displayed in Table (2).

Table (2): Speech discrimination analysis (\%) for control and study groups

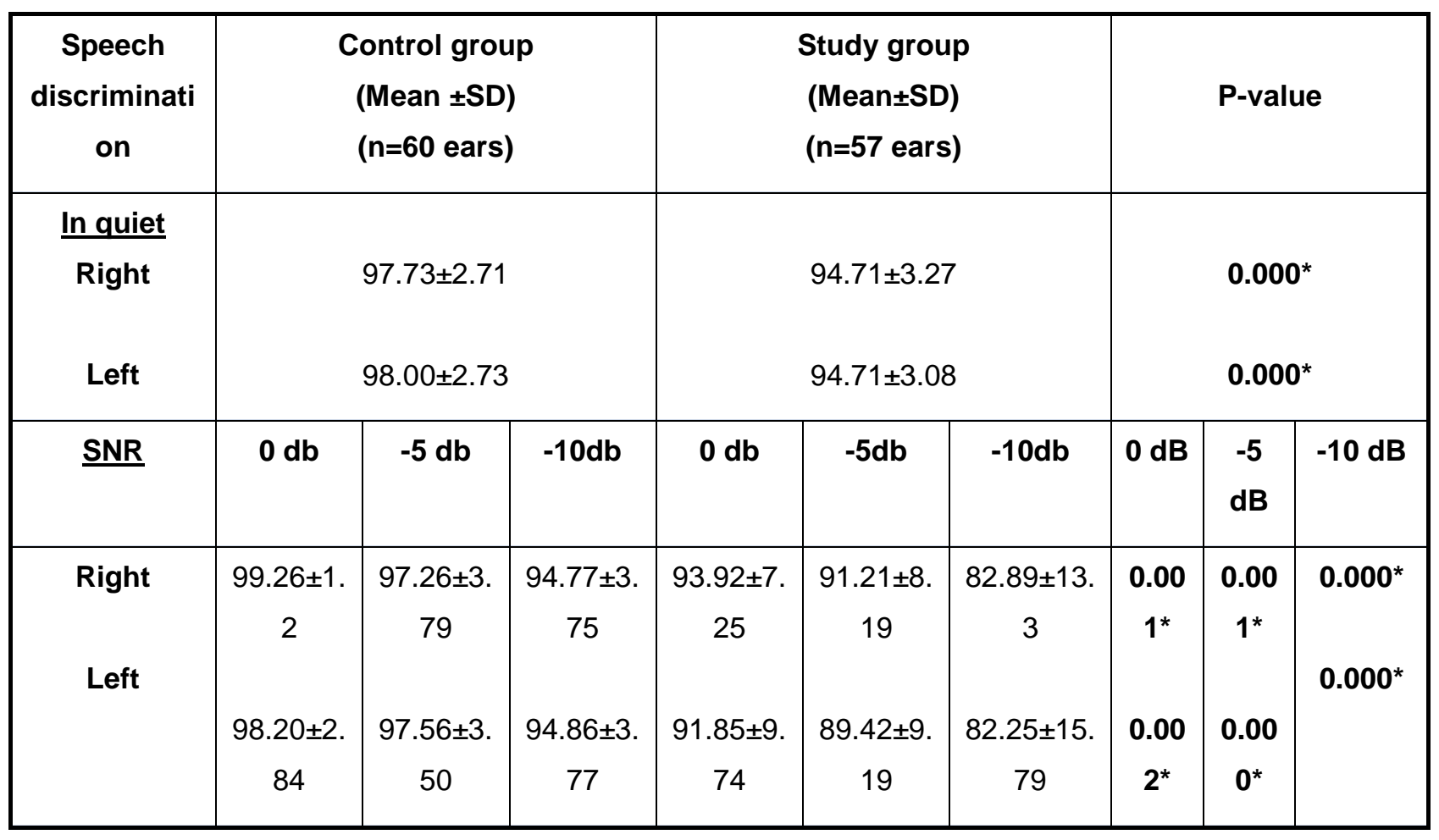

* = Statistically significant at $\mathrm{P}<0.05$.

Three ears were excluded from further analysis as they demonstrated moderately severe hearing loss because of the expected effect of large Air-Bone gap on ABR latencies.

-Regarding click ABR, there were statistically significant latency shift in the study group when compared to the control group in absolute latencies of waves III $(p=0.04)$ and $V(p=0.000)$ on the right side and wave $I(p=0.003)$ and $V(p=0.000)$ on the left side as shown in Table (3). 
-The same statistically significant difference were present regarding the interpeak latencies I-V ( $p=0.001)$ and III-V ( $\mathrm{p}=0.001)$ on the right side and III-V ( only on the left side as shown in Table (4). However, comparing the amplitude of the waves I, III, V between the study and the control groups revealed nonsignificant change $(p>0.05)$ in both sides.

Table (3):Click ABR absolute latencies (ms) and amplitude (mv) of wave I, III, V in both groups.

\begin{tabular}{|c|c|c|c|c|c|c|c|c|c|}
\hline \multirow[b]{2}{*}{ Wave } & \multicolumn{3}{|c|}{$\begin{array}{l}\text { Control Group) } \\
\text { ( } n=60 \text { ears) }\end{array}$} & \multicolumn{3}{|c|}{$\begin{array}{l}\text { Study Group } \\
\text { ( } n=57 \text { ears) }\end{array}$} & \multicolumn{3}{|c|}{ P-value } \\
\hline & I & III & V & I & III & V & I & III & V \\
\hline $\begin{array}{l}\text { Latenc } \\
\text { Right } \\
\text { Mean } \\
\pm \text { SD }\end{array}$ & $\begin{array}{l}1.54 \\
0.22\end{array}$ & \begin{tabular}{|l|}
3.6 \\
0.23
\end{tabular} & $\begin{array}{l}5.37 \\
0.39\end{array}$ & $\begin{array}{l}1.67 \\
0.28\end{array}$ & $\begin{array}{l}3.7 \\
0.28\end{array}$ & \begin{tabular}{|l|}
5.8 \\
0.55
\end{tabular} & 0.05 & $0.04^{\star}$ & $0.000^{*}$ \\
\hline $\begin{array}{l}\text { Left } \\
\text { Mean } \\
\pm \text { SD }\end{array}$ & \begin{tabular}{|l|}
1.5 \\
0.13
\end{tabular} & $\begin{array}{l}3.61 \\
0.29\end{array}$ & $\begin{array}{l}5.28 \\
0.36\end{array}$ & $\begin{array}{l}1.66 \\
0.28\end{array}$ & $\begin{array}{l}3.75 \\
0.27\end{array}$ & $\begin{array}{l}5.83 \\
0.58\end{array}$ & $0.003^{\star}$ & 0.07 & $0.000^{\star}$ \\
\hline
\end{tabular}

*= Statistically significant at $\mathrm{P}<0.05$.

Table (4): Click ABR interpeak latencies (I-III), (I-V), (III-V) in control and study groups.

\begin{tabular}{|c|c|c|c|c|c|c|c|c|c|}
\hline \multirow{2}{*}{$\begin{array}{l}\text { Interpeak } \\
\text { Latencies } \\
\text { (ms) }\end{array}$} & \multicolumn{3}{|c|}{$\begin{array}{l}\text { Control Group } \\
\text { (Mean } \pm \text { SD) } \\
(n=60 \text { ears) }\end{array}$} & \multicolumn{3}{|c|}{$\begin{array}{l}\text { Study Group } \\
\text { (Mean } \pm \text { SD) } \\
(n=57 \text { ears) }\end{array}$} & \multicolumn{3}{|c|}{ P-Value } \\
\hline & I-V & |-III & IIII-V & IIV & I-III & III-V & I-V & I-III & IIII-V \\
\hline $\begin{array}{l}\text { Right ear } \\
\text { Mean } \\
\pm S D\end{array}$ & $\begin{array}{l}3.80 \\
0.38\end{array}$ & $\begin{array}{l}2.07 \\
0.21\end{array}$ & $\begin{array}{l}1.77 \\
0.39\end{array}$ & \begin{tabular}{|l|}
4.25 \\
0.53
\end{tabular} & $\begin{array}{l}2.07 \\
0.34\end{array}$ & $\begin{array}{l}2.17 \\
0.46\end{array}$ & $0.001^{*}$ & 0.94 & $0.001^{*}$ \\
\hline
\end{tabular}




\begin{tabular}{|l|l|l|l|l|l|l|l|l|l|}
\hline Left ear & & & & & & & & & \\
Mean & 3.80 & 2.16 & 1.60 & 4.09 & 2.12 & 2.07 & 0.063 & 0.62 & $\mathbf{0 . 0 0 3}^{\star}$ \\
\pm SD & 0.32 & 0.37 & 0.54 & 0.79 & 0.25 & 0.56 & & & \\
\hline
\end{tabular}

* = Statistically significant at $\mathrm{P}<0.05$.

-Speech ABR test showed statistically significant latency shift in the study group, when compared to the control group in wave $V$ latency only $(p=0.000)$ for both sides, wave $A$ latency $(p=0.000)$ for both sides with significant reduced wave $A$ amplitude ( $p=0.007$ for right side and $p=0.023$ for left side). Meanwhile, the $V-A$ complex slope revealed statistically significant reduction (more shallower slope) in study group when compared to control group in both sides $(p=0.016$ for right side and $p=0.009$ for left side) but $V$-A complex duration showed non-significant change as displayed in Table (5).

Table (5): Speech ABR analysis on both sides in the control and study groups.

\begin{tabular}{|c|c|c|c|c|c|}
\hline $\begin{array}{l}\text { Speech } \\
\text { parameters }\end{array}$ & BR & mplex & \multirow{2}{*}{\begin{tabular}{|l}
$\begin{array}{l}\text { Control group } \\
\text { (Mean } \pm \text { SD) } \\
(n=60 \text { ears) }\end{array}$ \\
$5.74 \pm 0.36$ \\
$5.81 \pm 0.32$ \\
\end{tabular}} & \multirow{2}{*}{ 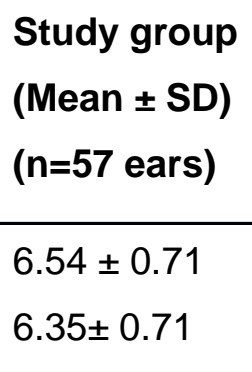 } & \multirow{2}{*}{$\begin{array}{l}P \text {-value } \\
0.000^{\star} \\
0.000^{\star}\end{array}$} \\
\hline Wave & Latency (ms) & $\begin{array}{l}R \\
L\end{array}$ & & & \\
\hline V & Amplitude(mv) & $\begin{array}{l}R \\
L\end{array}$ & $\begin{array}{l}0.12 \pm 0.08 \\
0.16 \pm 0.15\end{array}$ & $\begin{array}{l}0.11 \pm 0.07 \\
0.11 \pm 0.09\end{array}$ & $\begin{array}{l}0.701 \\
0.093\end{array}$ \\
\hline \multirow{2}{*}{$\begin{array}{l}\text { Wave } \\
\text { A }\end{array}$} & Latency (ms) & $\begin{array}{l}\text { R } \\
\text { L }\end{array}$ & $\begin{array}{l}6.45 \pm 0.40 \\
6.48 \pm 0.34\end{array}$ & $\begin{array}{l}7.22 \pm 0.74 \\
7.10 \pm 0.78\end{array}$ & $\begin{array}{l}0.000^{\star} \\
0.000^{\star}\end{array}$ \\
\hline & Amplitude(mv) & $\begin{array}{l}R \\
L\end{array}$ & $\begin{array}{l}0.21 \pm 0.09 \\
0.23 \pm 0.13\end{array}$ & $\begin{array}{l}0.14 \pm 0.09 \\
0.15 \pm 0.11\end{array}$ & $\begin{array}{l}0.007^{\star} \\
0.023^{\star}\end{array}$ \\
\hline \multirow{2}{*}{$\begin{array}{l}\text { V- A } \\
\text { Complex }\end{array}$} & Duration (ms) & $\begin{array}{l}R \\
L\end{array}$ & $\begin{array}{l}0.71 \pm 0.23 \\
0.69 \pm 0.19\end{array}$ & $\begin{array}{l}0.68 \pm 0.2 \\
0.74 \pm 0.19\end{array}$ & $\begin{array}{l}0.504 \\
0.344\end{array}$ \\
\hline & Slope & $\mathbf{R}$ & $0.48 \pm 0.18$ & $0.37 \pm 0.15$ & $0.016^{*}$ \\
\hline
\end{tabular}




\begin{tabular}{|l|l|l|l|l|l|}
\hline & & L & $0.59 \pm 0.35$ & $0.39 \pm 0.23$ & $\mathbf{0 . 0 0 9 *}$ \\
\hline
\end{tabular}

* = Statistically significant at $\mathrm{P}<0.05$.

To assess the possible contributing factors for the statistically significant difference between the control and study groups; SPIN, click ABR and speech $A B R$ tests were analyzed (by using logistic linear regression) and the following findings were found: Regarding the SPIN test the duration of the disease was a possible contributing factor i.e. the more the frequency of attacks of OME the worse the discrimination in SPIN test at $-5 \mathrm{~dB}$ and $-10 \mathrm{~dB}$ $\operatorname{SNR}(p=0.019$ and 0.037 respectively).The same for the scholastic underachievement of children in the study groups i.e. the worse the scores of SPIN test at $0 \mathrm{~dB},-5 \mathrm{~dB}$ and $-10 \mathrm{~dB} \operatorname{SNR}(\mathrm{p}=0.004,0.000$ and 0.000 respectively) the more the child scholastic underachievement (Figure 2). Click ABR also show association with child scholastic underachievement i.e. the more the child scholastic underachievement, the more the delay in absolute latency of wave $\mathrm{V}(\mathrm{p}=0.008)$ and the more prolonged III-V interpeak latency $(p=0.011)$. Also hearing level had a significant change in the study group affecting only absolute latency of wave $V(p=0.008)$ i.e. the more the hearing loss the more wave $\mathrm{V}$ latency delay. However, age, gender and balance problems were not correlated to significant difference between control and study groups.

Table (6): Possible factors affecting speech ABR latencies and amplitude

\begin{tabular}{|l|c|c|c|}
\hline Contributing factors & $\begin{array}{c}\boldsymbol{\beta} \text { (Wave V latency } \\
\text { speech ABR) } \\
\text { (p-value) }\end{array}$ & $\begin{array}{c}\boldsymbol{\beta} \text { (Wave A latency } \\
\text { speech ABR) } \\
\text { (p-value) }\end{array}$ & $\begin{array}{c}\boldsymbol{\beta} \text { (VA complex } \\
\text { slope) } \\
\text { (p-value) }\end{array}$ \\
\hline -Age & $0.527(\mathbf{0 . 0 0 5})^{\star}$ & $0.466(\mathbf{0 . 0 1 5})^{\star}$ & $0.180(0.394)$ \\
-Sex & $0.108(0.375)$ & $0.960(0.443)$ & $0100(0.480)$ \\
-Duration of the disease & $0.386(\mathbf{0 . 0 2 1})^{\star}$ & $0.281(0.095)$ & $0.076(0.687)$ \\
-Age at first attack & $-0.964(\mathbf{0 . 0 0 0})^{\star}$ & $-0.903(\mathbf{0 . 0 0 0})^{\star}$ & $0.236(0.361)$ \\
-Scholastic under & $0.354(\mathbf{0 . 0 1 7})^{\star}$ & $0.362(\mathbf{0 . 0 1 6})^{\star}$ & $0.050(0.762)$ \\
achievement & & & \\
-Balance problem & $0.025(0.844)$ & $0.006(0.963)$ & $0.116(0.440)$ \\
-Hearing level & $0.398(\mathbf{0 . 0 0 4})^{\star}$ & $0.337(\mathbf{0 . 0 1 5})^{\star}$ & $0.145(0.343)$ \\
\hline
\end{tabular}

$\boldsymbol{\beta}=$ Beta standardized coefficients $^{*}=$ Statistically significant at $P<0.05$. Regarding the SPIN test and scholastic underachievement, the worse the scores of SPIN 
test at $0 \mathrm{~dB},-5 \mathrm{~dB}$ and $-10 \mathrm{~dB} \operatorname{SNR}(\mathrm{p}=0.004,0.000$ and 0.000 respectively) the more the child scholastic underachievement (Figure 2).

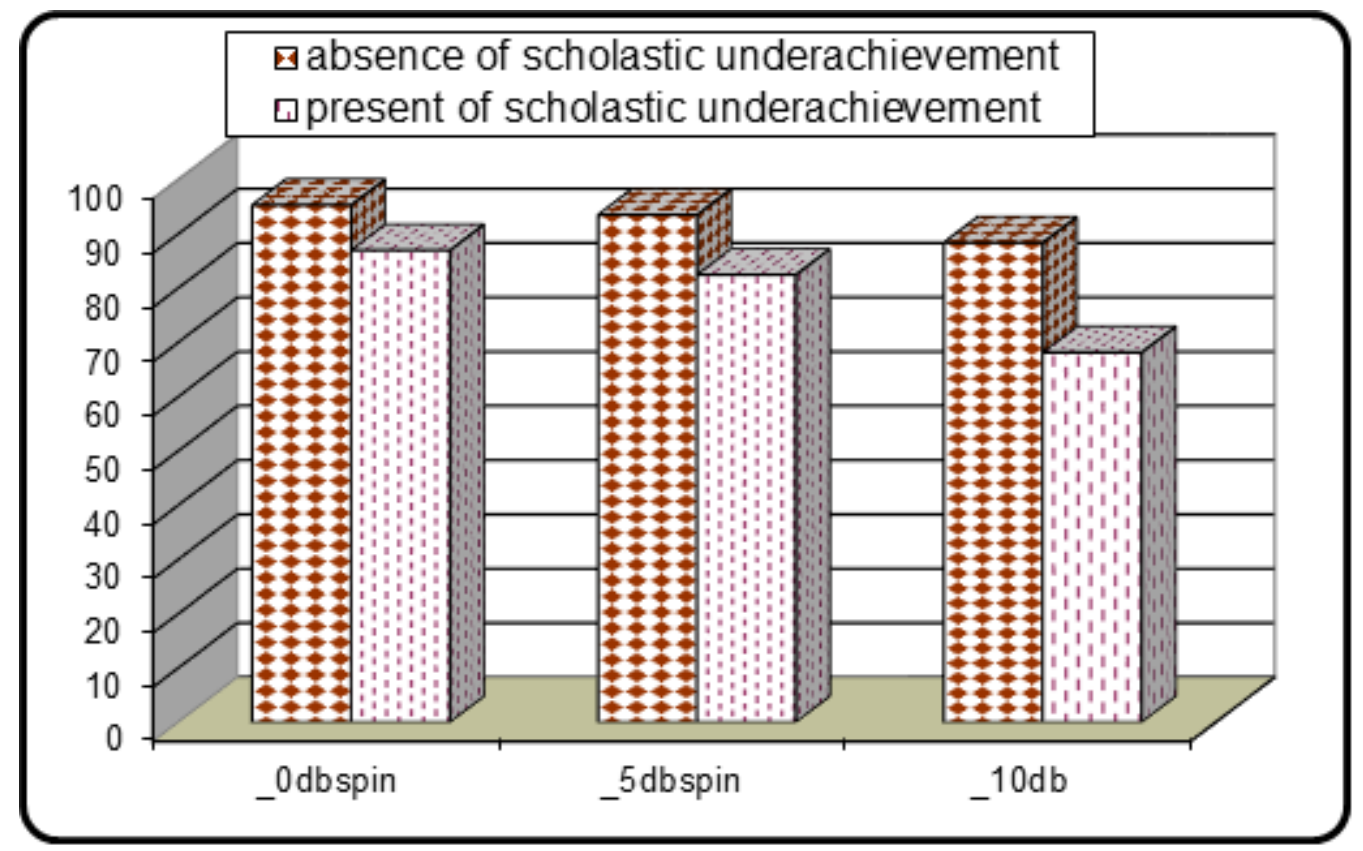

Figure (2): Comparison between scores of SPIN test at $0 \mathrm{~dB},-5 \mathrm{~dB}$ and $-10 \mathrm{~dB}$ SNR and the scholastic underachievement of the study group.

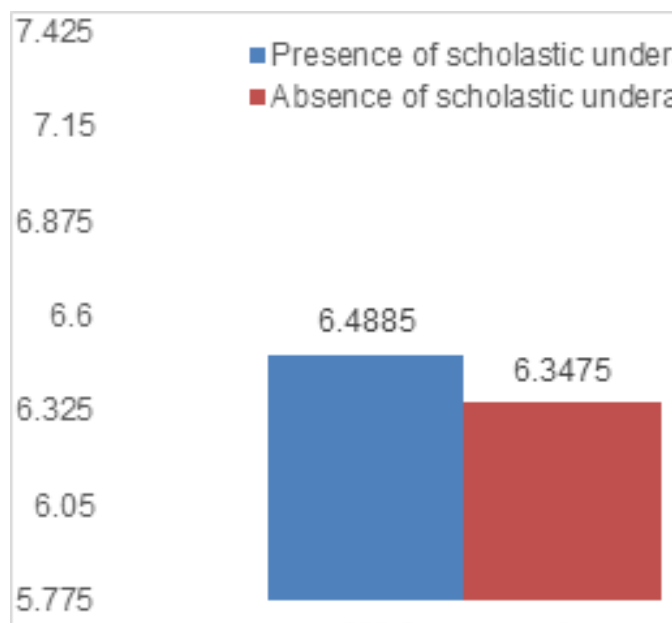

V latencyspeech

\subsection{8}

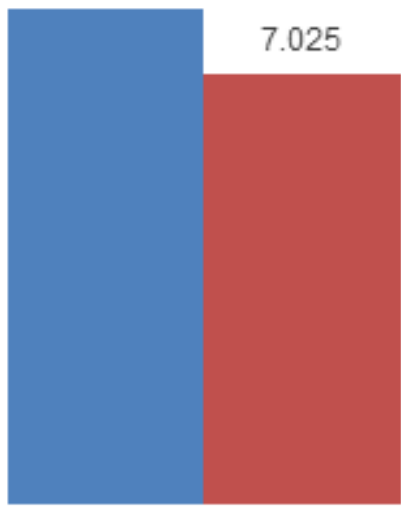

A latencyspeech

Figure (3): Comparison between Speech $A B R$ wave $V$ and wave $A$ latencies with scholastic underachievement of the study group. 
To assess the correlation between the electrophysiological and behavioral tests in children with history of recurrent OME further correlations were done:

-Correlation between SPIN and click ABR absolute and interpeak latencies (Table 7).

- Correlation between SPIN test and speech ABR was done and it revealed statistically significant negative correlation between speech $A B R$ latency of wave $V$ with the scores of SPIN test. Also between speech ABR latency of wave $A$ with the scores of SPIN test (Table 8).

Table (7): Correlation between SPIN and click ABR absolute and interpeak latencies (ms).

\begin{tabular}{|c|c|c|c|c|}
\hline \multicolumn{2}{|c|}{ Test parameters } & \multirow{2}{*}{\begin{tabular}{|l}
$\begin{array}{l}0 \mathrm{~dB} \text { SPIN } \\
(r) p \text {-value }\end{array}$ \\
-0.220 \\
$0.018^{\star}$ \\
\end{tabular}} & \multirow{2}{*}{\begin{tabular}{|l|}
$-5 \mathrm{~dB}$ SPIN \\
(r) p-value
\end{tabular}} & \multirow{2}{*}{\begin{tabular}{|l|}
$-10 \mathrm{dBSPIN}$ \\
$(\mathrm{r}) \mathrm{p}$-value
\end{tabular}} \\
\hline Wave I & $\begin{array}{l}(r) \\
p \text {-value }\end{array}$ & & & \\
\hline Wave III & $\begin{array}{l}(r) \\
p \text {-value }\end{array}$ & $\begin{array}{l}-0.016 \\
0.866\end{array}$ & $\begin{array}{l}-0.044 \\
0.643\end{array}$ & $\begin{array}{l}-0.089 \\
0.345\end{array}$ \\
\hline Wave V & $\begin{array}{l}(r) \\
p \text {-value }\end{array}$ & $\begin{array}{l}-0.178 \\
0.056\end{array}$ & $\begin{array}{l}-0.136 \\
0.146\end{array}$ & $\begin{array}{l}-0.165 \\
0.076\end{array}$ \\
\hline Wave III-V & $\begin{array}{l}(r) \\
p \text {-value }\end{array}$ & $\begin{array}{l}-0.171 \\
0.067\end{array}$ & $\begin{array}{l}-0.099 \\
0.290\end{array}$ & $\begin{array}{l}-0.116 \\
0.217\end{array}$ \\
\hline Wave I-III & $\begin{array}{l}(r) \\
p \text {-value }\end{array}$ & $\begin{array}{l}-0.295 \\
0.001^{*}\end{array}$ & $\begin{array}{l}-0.301 \\
0.001^{*}\end{array}$ & $\begin{array}{l}-0.264 \\
0.004^{\star}\end{array}$ \\
\hline Wave I-V & $\begin{array}{l}(r) \\
p \text {-value }\end{array}$ & $\begin{array}{l}0.037 \\
0.690\end{array}$ & $\begin{array}{l}0.081 \\
0.387\end{array}$ & $\begin{array}{l}0.039 \\
0.679\end{array}$ \\
\hline
\end{tabular}

$(r)=$ Pearson correlation $\quad{ }^{*}=$ statistically significant at $P<0.05$.

Table (8): Correlation between SPIN and speech ABR parameters

\begin{tabular}{|l|l|l|l|l|}
\hline Test parameters & $0 \mathrm{~dB}$ SNR & $-5 \mathrm{~dB}$ SNR & $-10 \mathrm{db}$ SNR \\
\hline
\end{tabular}




\begin{tabular}{|l|l|l|l|l|}
\hline Wave V latency & $(r)$ & -0.290 & -0.256 & -0.261 \\
& $p$-value & $\mathbf{0 . 0 0 2 ^ { \star }}$ & 0.006 & $\mathbf{0 . 0 0 5}$ \\
\hline Wave A latency & $(r)$ & -0.267 & -0.233 & -0.251 \\
& $p$-value & $\mathbf{0 . 0 0 4 ^ { \star }}$ & $\mathbf{0 . 0 1 2 ^ { \star }}$ & $\mathbf{0 . 0 0 7 ^ { \star }}$ \\
\hline Wave V amplitude & $(r)$ & 0.104 & 0.163 & $\mathbf{0 . 1 9 8}$ \\
& $p$-value & 0.266 & 0.081 & $0.033^{\star}$ \\
\hline Wave A amplitude & $(r)$ & 0.251 & 0.290 & 0.276 \\
& $p$-value & $\mathbf{0 . 0 0 7 ^ { \star }}$ & $\mathbf{0 . 0 0 2 ^ { \star }}$ & $\mathbf{0 . 0 0 3 ^ { \star }}$ \\
\hline V-A complex Slope & $(r)$ & 0.290 & 0.344 & $\mathbf{0 . 3 7 1}$ \\
& $p$-value & $\mathbf{0 . 0 0 2 ^ { \star }}$ & $\mathbf{0 . 0 0 0 ^ { \star }}$ & $\mathbf{0 . 0 0 0 ^ { \star }}$ \\
\hline V-A complex & $(r)$ & 0.191 & 0.220 & 0.128 \\
duration & $p$-value & 0.311 & 0.242 & 0.499 \\
\hline
\end{tabular}

$(r)=$ Pearson correlation, ${ }^{*}=$ statistically significant at $\mathrm{P}<0.05$.

-Correlation between speech ABR wave $\mathrm{V}, \mathrm{A}$ and age of onset of the disease (Figure 4 and 5) revealed the earlier the onset of the disease the more the delay in wave $\mathrm{V}$ and $\mathrm{A}$ latencies. 


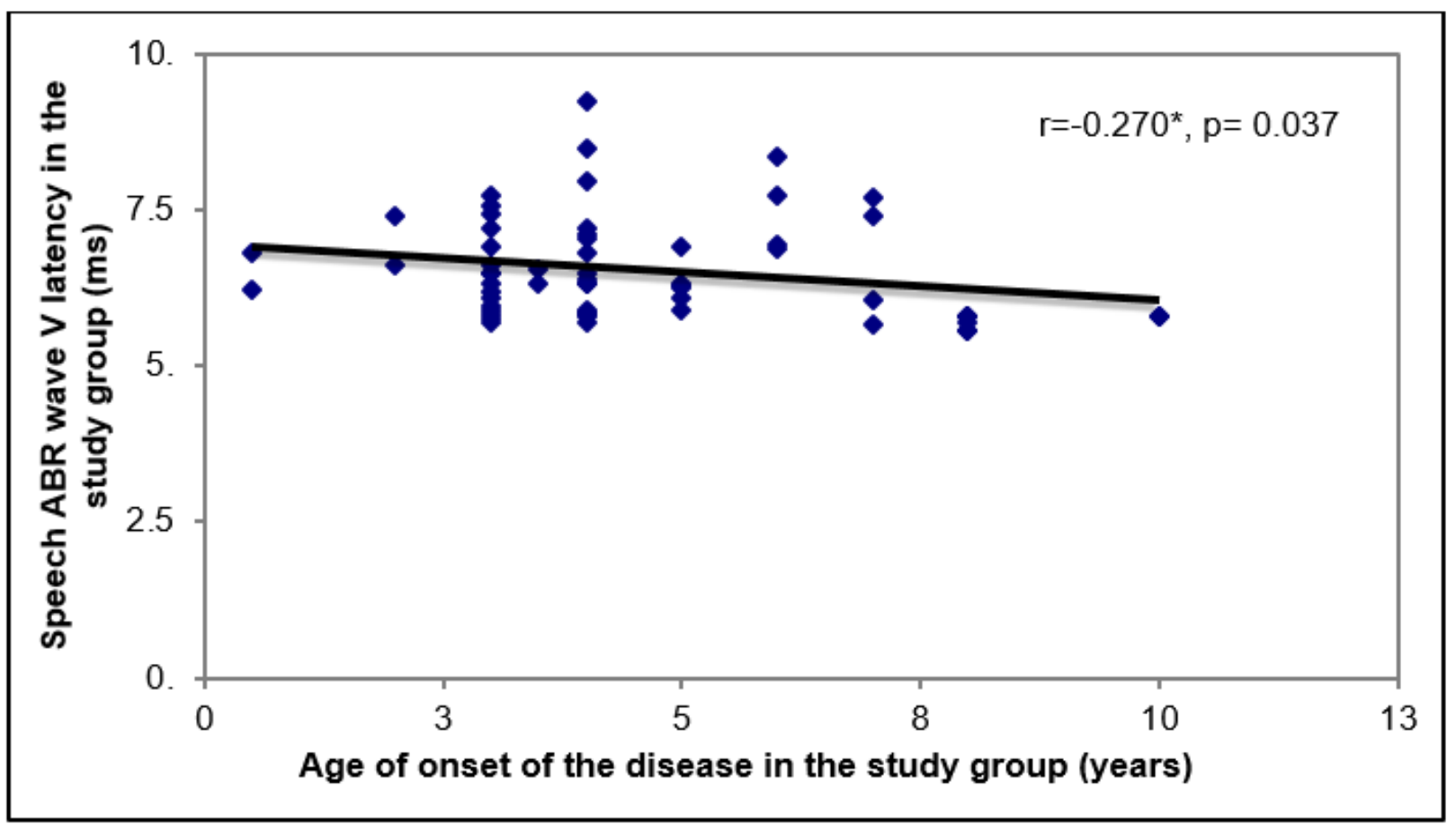

Figure (4): Correlation between speech ABR wave V latency and age of onset of the disease in the study group.

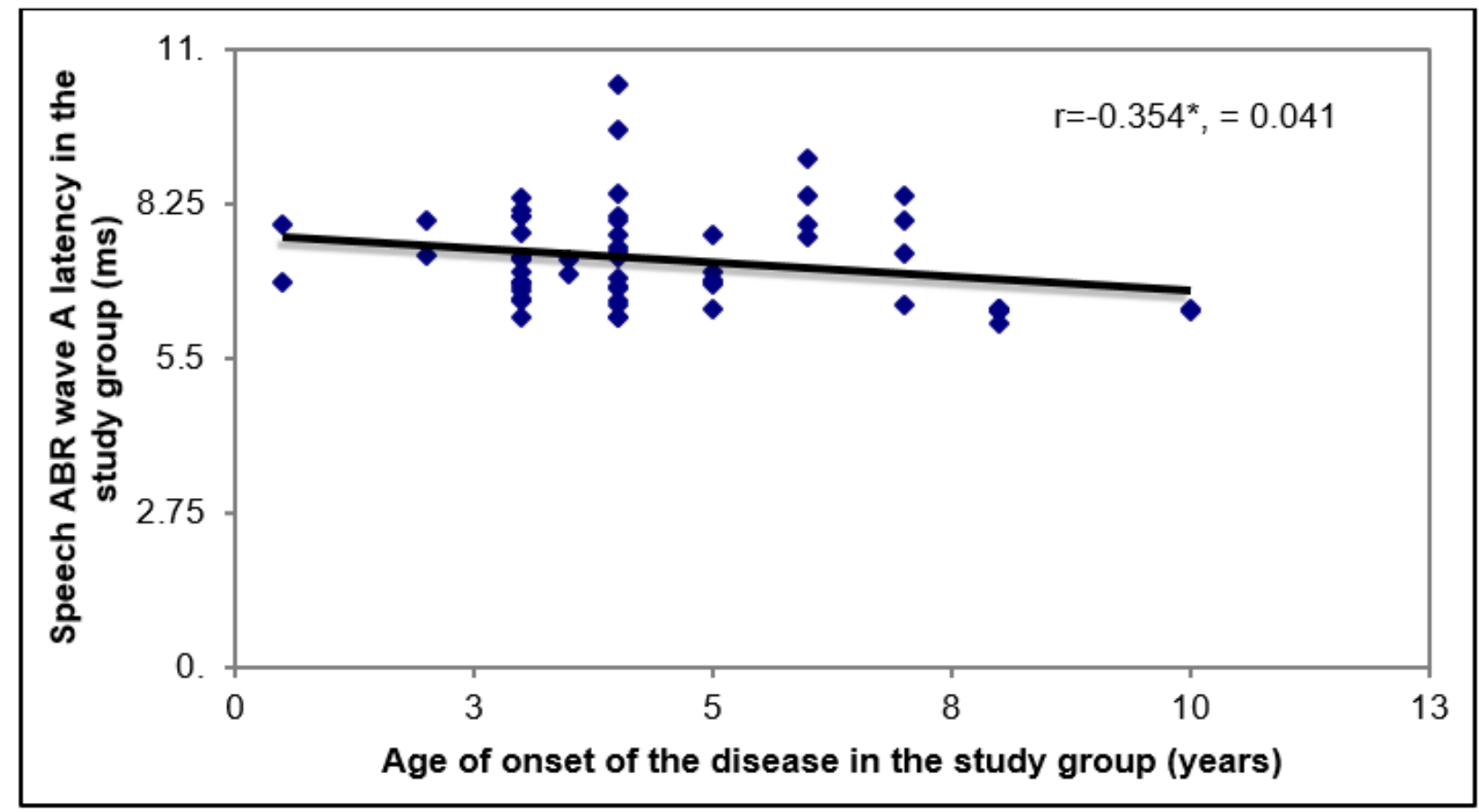

Figure (5): Correlation between speech ABR wave $A$ and age of onset of the disease in the study group. 


\section{Effect of recurrent OM:}

To study the effect of recurrent OM, a comparison was obtained between children of the control group and those in the study group whose average hearing threshold level at $(0.5 \mathrm{kHz}, 1 \mathrm{kHz}, 2 \mathrm{kHz}$ and $4 \mathrm{kHz})$ were within normal (subgroup 1). This comparison was done as regard:

\section{a) Speech discrimination:}

Speech discrimination test in quiet revealed a statistically significant reduced scores in subgroup 1as compared with control group $(p=0.000)$. Meanwhile speech perception in noise revealed the same statistically significant difference between those both groups at SNR $0 \mathrm{~dB},-5 \mathrm{~dB}$ and at $-10 \mathrm{~dB}(\mathrm{p}=0.000)$.

\section{b) Click ABR;}

Regarding click ABR, there was no statistically significant difference between the control group and subgroup 1 in absolute latencies of waves I $(p=0.05)$, III and $V(p>0.05)$ (Table 17) while the interpeak latencies showed statistically significant latency shift among I-V $(p=0.012)$ and III-V $(p=0.001)$.

\section{c) Speech ABR;}

The speech ABR showed statistically significant difference between control and subgroup 1 as regard wave $V$ latency only $(p=0.000)$, wave $A$ latency $(p=0.000)$, wave $A$ amplitude $(p=0.032), V-A$ complex duration $(p=0.027)$ and slope $(p=0.000)$ as shown in Table () .

Table (9): Comparison of speech ABR parameter in control group and Subgroup1 \{Children with recurrent OM having normal hearing (subgroup $1)\}$.

\begin{tabular}{|l|l|c|c|c|}
\hline \multicolumn{2}{|l|}{ Speech ABR parameters } & $\begin{array}{c}\text { Control group } \\
\text { (Mean } \pm \text { SD) } \\
\text { (n=60 ears) }\end{array}$ & $\begin{array}{c}\text { Subgroup 1 } \\
\text { (Mean } \pm \text { SD) } \\
\text { (n=26 ears) }\end{array}$ & P- VALUE \\
\hline \multirow{2}{*}{$\begin{array}{l}\text { Wave } \\
\text { V }\end{array}$} & Latency & $5.77 \pm 0.34$ & $6.22 \pm 0.59$ & $\mathbf{0 . 0 0 0}^{*}$ \\
\cline { 2 - 5 } & Amplitude & $0.14 \pm 0.13$ & $0.09 \pm 0.045$ & 0.074 \\
\hline
\end{tabular}




\begin{tabular}{|l|l|c|c|c|}
\hline \multirow{2}{*}{$\begin{array}{l}\text { Wave } \\
\text { V- A }\end{array}$} & Latency & $6.47 \pm 0.37$ & $6.94 \pm 0.62$ & $\mathbf{0 . 0 0 0}^{\boldsymbol{*}}$ \\
\cline { 2 - 5 } Complex & Amplitude & $0.22 \pm 0.12$ & $0.16 \pm 0.10$ & $\mathbf{0 . 0 3 2}^{\boldsymbol{*}}$ \\
\cline { 2 - 5 } & Duration & $0.59 \pm 0.24$ & $0.72 \pm 0.19$ & $\mathbf{0 . 0 2 7}^{\boldsymbol{}}$ \\
\hline
\end{tabular}

${ }^{*}=$ Statistically significant at $\mathrm{P}<0.05$.

\section{Effect of hearing threshold:}

To study the effect of hearing threshold variation in the study group, children with normal average hearing threshold; subgroup 1 was compared with those with variable degree of hearing loss; subgroups $2 \mathrm{a}, 2 \mathrm{~b}$ and $2 \mathrm{c}$ only excluding the moderately severe ears (subgroup $2 \mathrm{~d}$ ). The comparison revealed a surprising non-significant difference in speech perception in noise at $0 \mathrm{~dB},-5 \mathrm{~dB}$ and-10 dB SNR ( $p>0.05$ ). Also in click $A B R$, absolute latency of wave I $(p=0.526)$ but there were statistically significant difference in click ABR absolute latencies of wave III $(p=0.030)$ and wave $V(p=0.037)$. Regarding the speech $A B R$, there were non-significant change in all speech ABR parameters except wave V latency $(p=0.020)$.

\section{DISCUSSION}

Children with long-term otitis media with effusion (OME) provide strong evidence for changes in auditory processing acquired through altered experience (deprivation) and brain plasticity (11). Auditory deprivation due to otitis media has been suggested to underlie a maturational delay which may be related to auditory processing problems (12). One of the most common characteristics of individuals with central auditory processing disorder (CAPD) is the adverse effect of background noise on communication.

In the current study, SPIN test revealed depressed scores among the children with recurrent $\mathrm{OM}$ when comparing their scores with the control group. However, CHL was not associated with depressed scores of SPIN test as it is a suprathreshold test. Significant depressed SPIN scores occur in children with OME 
even in the absence of CHL. Same results were found when SPIN test was done for children having language-based problems and those who have auditory disorders such as, children with history of otitis media (13), specific language impairment (14), dyslexia (15), learning disabilities (16), and auditory processing disorder (17). All the previous studies showed similar speech perception difficulties in noise which were worse in the study groups than in normal control groups.

In the present study, our results agreed with Roberts et al. (18) who reported that $\mathrm{CHL}$ present in otitis media may cause asymmetry in the hearing levels of the ears, as would be the case when otitis media is present in only one ear. This asymmetry may have a negative effect on complex auditory processing (e.g. in binaural hearing), which may continue after hearing loss has resolved. Measures thought to be related to the ability to detect speech in background noise have also been shown to be affected in children with otitis media, even when hearing levels have returned to normal.

For click ABR, absolute latencies of wave I, III and V and interpeak latencies I-V and III-V were significantly prolonged in children with history of OME than in the control group. The absolute latency shift could be explained by the presence of $\mathrm{CHL}$ in the study group. However, the delay in wave $\mathrm{V}$ was more relevant and was the cause of significant I-V and III-V interpeak latency shift in both ears in the study group. This delay was not due to $\mathrm{CHL}$ as it is still present in children of the study group having normal hearing. The delay in III-V interpeak latency in those children reflects upper brainstem transmission delay.

Past researches have demonstrated that early $\mathrm{OM}$ in children influences auditory brainstem. They reported a reduction in both the size and number of neurons in the auditory brainstem in subjects with OM (19). Delayed wave III and V, and prolonged interpeak intervals $\mathrm{I}-\mathrm{III}$ and III-V were the most common findings reported in past research on children with early onset $\mathrm{OM}$ as documented by Falson (20). Lendhart (21) and Chambers (22) noted delayed absolute latency of wave III and V and I-III interpeak latency only. Owen (23) reported delayed 
absolute latencies for wave I, III and V and III-V interpeak latency only. On the other hand, Hall et al., (24) noted delayed absolute latencies of wave III and V and reported non-significant changes on interpeak latencies. Our results agreed with Sandeep and Jayaram (19) who documented prolonged absolute latencies for wave III and wave V, prolonged III-V and I-V interpeak latencies for children with OM when compared with control group.

Regarding Speech $A B R$, the speech-evoked wave $V$ is analogous to the clickevoked wave $\mathrm{V}$, although possibly generated by different mechanisms. Wave $\mathrm{A}$ is the trough following wave $\mathrm{V}$ and the VA slope is calculated by triangulating the latencies and amplitudes of the two peaks. Thus, earlier responses and sharper slopes are indicative of more precise brainstem timing and these three metrics have been repeatedly shown to be the most fruitful in differentiating poor readers from good ones. Brainstem encoding of speech is a significant factor contributing to both speech perception in noise and reading in school-aged children. Nevertheless, these skills appear to have substantially distinct neural indices (25).

In the present study, children with history of recurrent OME demonstrated a poorer representation of speech than typically developing children. There was a significant difference between study and control groups in terms of delayed wave $\mathrm{V}$ and $\mathrm{A}$ latencies, reduced wave $\mathrm{A}$ amplitude and shallower $\mathrm{V}-\mathrm{A}$ complex slope. Similar to click $\mathrm{ABR}, \mathrm{CHL}$ was associated with delay in wave $\mathrm{V}$ latency. However, this significant wave $\mathrm{V}$ latency shift together with wave $\mathrm{A}$ delay and reduced amplitude, prolonged $\mathrm{V}$-A duration and shallower slope were reported in children with recurrent OME and could be due to other causes than $\mathrm{CHL}$ as it was still present in absence of hearing loss. To date, no sufficient speech ABR data have been published in patients with recurrent OME. On the other hand, extensive research has been conducted in Learning-Disabled (LD) children. Accordingly, the data of the study group having history of OME will be compared to the LD children. 
In the present study, results of speech ABR in the study group, shared some similarity with other studies done on LD children. King et al. (26) compared the speech-evoked $A B R$ in normal children and children diagnosed with LD. They reported delayed onset response in the form of delayed wave $A$ latency only in children with LD even though they have normal response to $A B R$ click stimuli. They suggested that LD children have abnormalities in the acoustic representation of speech sound as low as the auditory brainstem. Hayes et al. (27) examined the plasticity of the central auditory pathway and accompanying cognitive changes in children with LD. Subcortical auditory pathway was assessed by measuring the latencies of the ABR elicited by click and speech stimuli. All subjects had wave $\mathrm{V}$ latencies within normal range. However $60 \%$ of LD children had delayed brainstem latency (wave A). Wible et al. (28) investigated how the human auditory brainstem represents constituent elements of speech sounds differently in children with language-based learning problems compared to normal children. They recorded that in response to the onset of the speech sound /da/, V-A complex slope had a significantly shallower slope in children with learning problems, suggesting longer duration and smaller amplitude. They reported that poor representation of crucial components of speech sounds could contribute to difficulties with higher-level language processes. Kraus and Nicol, (29) suggested that disruption of either the onset response of speech $A B R$ or the FFR is likely to result in impaired representation of important segmental and supra-segmental information, respectively, within the speech sound thus degrading the input into higher levels of the auditory system.

Song et al. (30) investigated the relationship between click and speech-evoked $A B R$ as recorded in normal children and those diagnosed with LD. They reported a characteristic delay between waves $\mathrm{V}$ and $\mathrm{A}$ and a reduced $\mathrm{V}$ - $\mathrm{A}$ complex slope. Abdelghaffar et al. (5) investigated click and speech evoked ABR in children with delayed language development. They reported a statistically significant delay in wave $\mathrm{V}$ and $\mathrm{A}$ latencies and decrease in their amplitude, prolonged $\mathrm{V}-\mathrm{A}$ 
complex duration and reduced slope in children with delayed language development. However no significant change was present in click ABR waves.

Waves $V$ and $A$ of speech $A B R$ are thought to be largely generated by the lateral lemniscus and/or inferior colliculus. Direct correlation between the structures of the brainstem and ABR waves cannot be made whereas these complex far-field responses most certainly reflect overlapping activities from multiple neural regions. Consequently, deficiencies in these local processes, mainly during critical developmental periods, could lead to changes in subcortical structures that then affect sensorineural coding of speech stimuli (31). Furthermore, the latter author suggested that the presence of abnormalities in lower levels of the auditory pathway might limit the effectiveness of processing acoustic information at the cortical level. These results reinforce the idea that the timing deficits reflected by the brainstem in electrophysiological measurements could affect the cortical processing of acoustic information. The acoustic structure of speech is characterized by rapidly changing spectral patterns. Thus, the reduced capability to process, understand and distinguish complex sounds could affect certain skills necessary for the normal development of language (25).

Age and gender did not reflect any significant difference between the control and study group in SPIN test, click ABR or speech ABR except for some maturational variation that affected wave $\mathrm{V}$ and $\mathrm{A}$ latencies; the older the child, the more prolonged wave $V$ and $A$ latencies of speech $A B R$. Moreover, if OM occurred early in life, it is associated with more absolute wave $\mathrm{V}$ latency and III-V interpeak latency delay in click $A B R$ together with more delay in wave $V$ and $A$ latencies in speech ABR. Same results were reported by Tawfik et al(32) and Abdelrahman et al.,(33). The duration of the disease was associated with significant depressed SPIN scores at $-5 \mathrm{~dB}$ and $-10 \mathrm{~dB}$ SNR, delayed absolute latency of wave $\mathrm{V}$ and III-V interpeak latency of click ABR and delayed wave $\mathrm{V}$ latency of speech ABR. Williams and Jacobs (34) stated that early onset of otitis media (under 12 months of age) and repeated attacks of OM together with 
long periods of infection increase the risk of sustaining long-term speech and language deficits as a consequence of OM. Moreover, Whitton and Polley, (35) stated that the primary risk factor for abnormalities in brain physiology, auditory perception, and speech receptivity that can accompany OM in childhood is not the presence of the disease state itself but the degradation of the afferent signal that can arise from early onset $\mathrm{OM}$. The presence and quality of sensory-evoked afferent input characterize the development of higher (i.e. midbrain, thalamic, and cortical) sensory brain areas and causes significant alterations in the response properties of individual neurons, as well as their coordinated arrangement into functional circuits and topographic maps.

The current study showed significant relation between scholastic underachievement and both the behavioral and the electrophysiological tests. It was frequent among the study group and represented about $1 / 3$ of them (30\%). It was associated with significantly depressed SPIN scores at $0 \mathrm{~dB},-5 \mathrm{~dB}$ and -10 $\mathrm{dB}$ SNR as well as click ABR absolute latency of wave $\mathrm{V}$ and III-V interpeak latency. The same for speech $A B R$ wave $V$ and $A$ latencies which showed significant shift with scholastic underachievement. This agreed with Nittrouer et al. (36) and Yathiraj and Mascarenhas (37) who found that OM negatively affects educational outcomes. If OM occurs during preschool years it will affect auditory processing skills. Therefore, children could find it difficult to process auditory information in the suboptimal listening conditions of the classroom. If speech perception is affected, phonemic awareness is also likely to be affected. This can, in turn, lead to difficulties with reading and spelling. If language development is affected, there can be long-term effects on reading and in particular on reading comprehension. Moreover, Williams and Jacobs (34) reported that a cumulative history of OM may affect various measures of attention, behavior, literacy skills and academic achievement which were still evident during adolescence. 
The present study revealed significant correlation between behavioral test (SPIN) and electrophysiological tests (click ABR and speech ABR) in children with recurrent OME. A significant negative correlation was found in the form of depressed SPIN scores with delayed absolute latency of wave I and I-III interpeak latency of click $A B R$ and delayed wave $V$ and $A$ latencies of speech $A B R$. $A$ significant positive correlation was reported in the form of depressed SPIN scores with reduced amplitude of wave $\mathrm{V}$, wave $\mathrm{A}$ and shallower $\mathrm{V}$-A complex slope of speech ABR.

In a trial to find a correlation between the 2 electrophysiological tests (click and speech $A B R$ ), this study revealed a positive correlation in the form of delayed wave I, III, V, I-V and III-V latencies of click ABR with delayed wave $\mathrm{V}$ and wave $\mathrm{A}$ latency of speech ABR. However, a negative correlation was found between wave $V$ and III-V latency of click ABR with reduced wave A amplitude and V-A complex slope (shallower slope) of speech ABR. Therefore, delay in the distal part of the auditory pathway (absolute latency of wave I and I-III interpeak latencies) was associated with reduced SPIN scores i.e. delayed lower brainstem transmission. While a delay in the proximal part of auditory pathway (absolute latency of wave $\mathrm{V}$ and III-V interpeak latencies) was associated with shallower V-A complex slope i.e. delayed upper brainstem transmission. Delay in any click ABR waves (absolute latency of wave I, III and V or III-V, I-V interpeak latencies) was associated with delay in speech $A B R$ onset response waves (wave $V$ and wave $A$ latencies).

The present study supports the hypothesis that there may be some shared processing reflected in the click and speech onset latency measures, there is also a separate component unique to the processing of complex auditory signals, such as speech (38).

Song et al (30) described that both click and speech stimuli evoke different responses, based on the acoustic characteristics of the evoking stimuli. Furthermore, they hypothesized that the speech stimulus may be more challenging to the auditory system because the periodic portion of the vowel may mask the 
abrupt onset of the consonant. Additionally, differences between the encoding of the click and the speech stimuli suggests that abnormal speech-evoked ABRs may be based on differences in synchronization of the response generators. Thus, if the brainstem is more sensitive to desynchronization effects, the impact will become apparent in response to the speech stimulus, which is longer in duration and has a more gradual onset than the click stimulus (28). Other studies have shown associations between the speech-evoked $A B R$ and both reading ability and speech recognition in noise; better reading ability and speech recognition in noise correlated with more robust neural responses (31).

The influence of sensory-evoked activity patterns on the formation of functional brain circuits is not expressed equally across development. Rather, afferent input patterns have the strongest instructive influence on neural response properties during finite "critical periods" of postnatal development, when those circuits are first forming. In the event that the presence of OM creates weak and temporally degraded sound-evoked activity patterns during critical periods of brain development, the adverse effects of these degraded signals on the formation of neural circuits that mediate perception and behavior could persist long after the middle ear pathology has resolved (35).The effect of diminished auditory sensitivity due to OME on a child's developing auditory system is an important issue for researchers as it may affect a child's linguistic, psychological and behavioral development (39).

\section{REFERENCES}

1. Sanfins M, Borges L, Ubiali T, Colello-Santos M (2017): Speech auditory brainstem response (speech $A B R$ ) in the differential diagnosis of scholastic difficulties Braz. j. otorhinolaryngol; 83. 


\section{El-Kabarity R, Abdel Rahman $\mathbf{T}$, Abdel Kader H, Sanyelbhaa H}

(2015): Effect of otitis media with effusion on brainstem timing in children. J Hearing, Balance and Communication; 14:20-24.

3. Jerger J, Musiek F (2000): Report of the consensus conference on the diagnosis of auditory processing disorders in school-aged children. J Am Acad Audiol; 11(9):467-474

4. Musiek F, Baran J, Schochat E (1999): Selected management approaches to central auditory processing disorders. Scandivian Audiology; 51: 63-76.

5. Abdel Ghaffar H, Reyad D, Selim M, Abdultawab M (2007): Speech and Click Evoked Auditory Brain-stem Response in Delayed Language Children with Normal Pure tone Audiogram. Med J Cairo Univ, 75(2): 193-199.

6. Maddox R, Lee A (2017): Auditory brainstem responses to continuous natural speech in human listeners. ENEURO.

7. Soliman S, Fathallah A, Shehata W (1985): Development of the Arabic Staggered Spondaic Words (SSW) test. Proceedings of the 8th Ain Shams Medical Congress; 2: 1220-1246.

8. Soliman S (1976): Speech discrimination audiometry using Arabic Phonetically-Balanced words. Ain Shams Medical Journal; 27: 27-30.

9. Soliman S, Tawfik S, Shalaby A (1995): Development and standardization of Arabic central test battery for children. Proceeding of XXII world congress of the International Association of Logopedics and Phoniatric; 416-419.

10. Clark J (1981): Uses and abuses of hearing loss classification. Asha; 23: $493-500$.

11. Moore D, Palmer A, Hall D, Sumner C (2007): Hearing research special issue "Auditory cortex 2006-the listening brain". Hearing Research; 239:1-12.

12. Chermak G, Silva M, Nye J, Hasbrouck J, Musiek F (2007): An update on professional education and clinical practices in central auditory processing. Journal of the American Academy of Audiology; 18(5): 428-452.

13. Zumach A, Gerrits E, Chenault M and Anteunis L (2009): otitis media and speech in noise recognition in school-aged children, Audiol. Neurootol; 14: 121-129. 
14. Ziegler J, Pech-Georgel C, George F, Alario F, Lorenzi C (2005): Deficits in speech perception predict later language learning impairment. Proceedings of the National Academy of Sciences of the United States of America;102(39): $14110-14115$.

15. Chandrasekaran, B, Hornickel J, Skoe E, Nicol T, Kraus N (2009): Context dependent encoding in the human auditory brainstem relates to hearing speech in noise: implications for developmental dyslexia. Neuron; 64: 311 319.

16. Bradlow et al., 2003 Bradlow AR, Kraus N, Hayes E (2003): Speaking clearly for children with learning disabilities: sentence perception in noise. $J$ Speech Lang Hear Res; 46, 80-97.

17. Johnston K, John A, Kreisman N, Hall III J, Crandell C (2009): Multiple benefits of personal FM system use by children with auditory processing disorder (APD). International Journal of Audiology; 48: 371-383.

18. Roberts J, Rosenfeld R, Zeisel S (2004): Otitis media and speech and language: a meta-analysis of prospective studies. Pediatrics; 113: 238-248.

19. Sandeep M and Jayaram M (2008): Effect of early onset otitis media on brainstem and cortical auditory processing. Behavioral and Brain Functions; 4:17-28.

20. Folsom R, Weber B, Thompson G (1983): Auditory brainstem responses and children with early recurrent middle ear disease. Ann Otorhinolaryngol; 92:249-253.

21. Lenhardt M, Shaia F, Abedi E (1985): Brain-stem evoked response waveform variation associated with recurrent otitis media. Arch Otolaryngol; 111:315-316. 
22. Chambers R, Rowan L, Matthies M, Novak M (1989): Auditory Brain-stem Responses in Children with Previous Otitis Media. Arch Otolaryngol Head Neck Surg; 115:452-457.

23. Owen M, Norcross-Nechay K, Howie V (1993): Brainstem auditory evoked potentials in young children before and after tympanostomy tube placement. Int J Pediatr Otorhinolaryngol; 25:105-117.

24. Hall J, Grose J, Dev M, Ghassi S (1998): The effect of masker interaural time delay on the masking level difference in children with history of normal hearing or history of otitis media with effusion. Ear Hear; 19:429-433.

25. Gonçalves I, Wertzner H, Samelli A, Matas C (2011): Speech and nonspeech processing in children with phonological disorders: an electrophysiological study. Clinics; 66(2):293-298.

26. King C, Warrier C, Hayes E, Kraus N (2002): Deficits in auditory brainstem encoding of speech sounds in children with learning problems. Neurosci Lett; 319:111-115.

27. Hayes E, Warrier C, Nicol T, Zecker S, Kraus N (2003): Neural plasticity following auditory training in children with learning problems. Clin Neurophysiol;114: 673-684.

28. Wible B, Nicol T, Kraus N (2004): Atypical brainstem representation of onset and format structure of speech sounds in children with language-based learning problems. Biological Psychology; 67: 299-317.

29. Kraus N, Nicol T (2005): Brainstem origins for cortical 'what' and 'where' pathways in the auditory system. Trends Neurosci; 28:176-181.

30. Song J, Banai K, Russo N, Kraus N (2006): On the relationship between speech and non-speech-evoked auditory brainstem responses. Audiology and Neurootology; 11:233-241. 
31. Hornickel J, Chandrasekaran B, Zecker S, Kraus N (2011): Auditory brainstem measures predict reading and speech-in-noise perception in school-aged children. Behavioral Brain Research; 216(2):597-605.

32. Tawfik S, Sadek I, Abdel-Maksoud A, Abumoussa H (2002): Auditory attention and memory tests for children: development, standardization and application. The Egyptian Journal of otolaryngology; 19 (2): 537-551.

33. Abdel-Rahman T, Hazaa N, Abdel-Maksoud A, El-Koli W (2011): Speech-evoked auditory brainstem and event related potentials: standardization and application in children with central auditory processing disorders. MD thesis, Ain Shams University.

34. Williams $\mathbf{C}$ and Jacobs $\mathbf{A}$ (2009): The impact of otitis media on cognitive and educational outcomes. MJA; 191: 69-72.

35. Whitton $\mathbf{J}$ and Polley D (2011): Evaluating the perceptual and pathophysiological consequences of auditory deprivation in early postnatal life. A comparison of basic and clinical studies. Association for Research in Otolaryngology; 12: 535-546.

36. Nittrouer S (1996): The relation between speech perception and phonemic awareness: evidence from low-SES children and children with chronic OM. J Speech Hearing Res; 39: 1059-1070.

37. Yathiraj A, Mascarenhas K (2003): Effect of early auditory stimulation in central auditory processing in children with CAPD. Unpublished project, All India Institute of Speech and Hearing, Mysore.

38. Kraus N, Nicol T (2003): Aggregate neural responses to speech sounds in the central auditory system. Speech Communication; 41: 35- 47.

39. Johnston C, Green W (2002): Auditory deprivation in children with otitis media with effusion and its effect on temporal resolution. Journal of SpeechLanguage Pathology and Audiology; 26: 197-209. 
